\title{
ARTICLE
}

\section{Causes of death among diabetic patients in Denmark}

\author{
M. B. Hansen • M. L. Jensen • B. Carstensen
}

Received: 30 June 2011 / Accepted: 19 October 2011 /Published online: 30 November 2011

(C) Springer-Verlag 2011

\begin{abstract}
Aims/hypothesis To study the distribution of causes of death in the Danish population, and its variation by diabetes status, sex, age and calendar year as well as the years of life lost from the specific causes of death.

Methods Persons aged 30-98 years were followed from 1995 to 2008 by linkage of Danish registers. Poisson regression was used to model cause-specific mortality rates by age and calendar time for each specific cause of death, according to sex and diabetes status. The mortality rates were also modelled as a function of age and birth cohort. We computed the distribution of causes of death and years of life lost from specific causes of death due to diabetes. Results During the 14-year study period, patients with diabetes contributed 2.3 million person-years of follow-up and 124,210 deaths, whereas persons without diabetes contributed 45.1 million person-years and 648,020 deaths. The mortality was higher among individuals with diabetes, and the mortality ratio (diabetes vs no diabetes) decreased with age and for all causes and cardiovascular diseases also by calendar time. The effect of sex on the association between diabetes and mortality varied with age and cause of death. About 9 years of life were lost to diabetes at age 30 years, and 3 years at age 70 years.

Conclusions/interpretation Age-specific mortality is higher among people with diabetes, and rate ratios vary with age, sex, calendar period and cause of death. The distribution of
\end{abstract}

Electronic supplementary material The online version of this article (doi:10.1007/s00125-011-2383-2) contains peer-reviewed but unedited supplementary material, which is available to authorised users.

M. B. Hansen · M. L. Jensen • B. Carstensen $(\bowtie)$

Steno Diabetes Center A/S, Niels Steensens Vej 2,

DK-2820 Gentofte, Denmark

e-mail: bxc@steno.dk causes of death was similar for persons with and without diabetes.

Keywords Causes of death · Demography · Mortality · Years of life lost

\section{Abbreviation \\ SMR Standardised mortality ratio}

\section{Introduction}

Several studies have found a higher all-cause mortality among patients with diabetes than among persons without diabetes [1-3]. Studies looking at cause-specific mortality have also reported a higher mortality among diabetic patients from most specific causes of death, but the association between diabetes and cancer, as well as with some respiratory diseases, is inconsistent across studies [1, 4-7].

Other previous studies have found that the association between diabetes and mortality varies across countries $[8,9]$. Only one Danish study exists, in which the association between diabetes and cause-specific mortality has been studied [10]. The aims of the present study were to study the association between diabetes and specific causes of death in the entire Danish population, and to see how age, sex and calendar time affected the association, as some previous studies have found that these factors affect the association between diabetes and mortality $[4,11,12]$.

We also wanted to compare the distribution of causes of death between individuals with and without diabetes. We based our study on the estimated distribution of causes of death from a statistical model for cause-specific mortality rates as the empirical distribution of causes of death is 
confounded by the age distribution in the population. To our knowledge, no previous study has estimated the distribution of causes of death. Finally, we estimated the years of life lost due to diabetes at different ages both from specific causes of death and in total.

Registers All persons with permanent residence in Denmark have a unique identification number (CPR-number) [13]. This unique identification number was used to link data from the Danish National Diabetes Register and the Danish Cause of Death Register. The size of the Danish population was obtained from Statistics Denmark for 1 January each year between 1995 and 2008 by sex and age.

The Danish Cause of Death Register was established in 1970 and includes all deaths among persons with residence in Denmark since 1970; the cause of death has been coded in ICD-10 (www.who.int/classifications/icd/en/) since 1984 [14].

The Danish National Diabetes Register was established in 2006 and contains all prevalent cases of diabetes up until 1 January 1995 and all incident cases of diabetes between 1 January 1995 and 31 December 2008 [15, 16]. The Register is not considered to be complete until 1995, and therefore only data from 1995 and onwards were included in the data analyses in this study. The Danish National Diabetes Register is based on administrative records, and therefore it is not possible to distinguish between type of diabetes [15]; hence, type of diabetes is not considered in this study.

\section{Methods}

All Danish individuals with and without diabetes who were aged 30-98 in the period 1995 to 2008 were followed up for mortality from 1 January 1995 until 31 December 2008. The study was restricted to ages 30-98 for practical reasons.

By linkage of the Danish National Diabetes Register and the Danish Cause of Death Register, it was possible to obtain the number of deaths by diabetes status. The number of deaths was tabulated by calendar time (3-year intervals), age (1-year intervals) at follow-up, diabetes status and sex. This was done for each specific cause of death. The causes of deaths were classified coarsely into five categories and in more detail into 18 categories (Table 1).

Person-years in the entire Danish population by sex, age and calendar year were based on population data from Statistics Denmark and tabulated in the same way as the number of deaths. The person-years among diabetic patients by sex, age and calendar year were computed as the time from inclusion on the Danish National Diabetes Register until death or 31 December 2008. The personyears for the non-diabetes group were obtained by subtracting the person-years for the diabetes group from the person-years in the corresponding sex, age and calendar-year group of the total Danish population.

Statistical methods Poisson regression for frequency tables was used to obtain mortality rates for specific causes of death by sex and diabetes status. Mortality rates $(\lambda)$ were first modelled as a function of attained age $(a)$ and calendar period $(p)$, using a Poisson model for the death counts with $\log$ person-years as offset:

$\log (\lambda)=f(a)+g(p)$

Age and period midpoints in each cell of the tables were used as continuous variables. The functions of age and period were taken as natural (cubic) splines. Functions $f(a)$ and $g(p)$ were constrained in such a way that $g(p)$ was zero in the reference year chosen, i.e. 2008. Thus, $f(a)$ referred to $(\log )$ age-specific mortality in the reference year, and $g(p)$ referred to the $(\log )$ mortality rate ratios relative to the reference year. The mortality rates were also modelled as a function of attained age ( $a)$ and birth cohort $(c=p-a)$ by:

$\log (\lambda)=f(a)+h(c)$

Here, $f(a)$ referred to the (log) age-specific mortality in the reference cohort, i.e. the 1940 birth cohort, and $h(c)$ referred to the (log) mortality rate ratios in other birth cohorts relative to the reference cohort. The mortality rates obtained from the age-cohort model is not reported because they were too uncertain as a result of birth cohort and age being highly correlated due to the short follow-up time (1995-2008).

To compare the mortality rates between persons with and without diabetes, the age-specific mortality rates from 2008 were used to compute mortality rate ratios (diabetes vs no diabetes) separately for males and females.

The estimated age-specific mortality rates from 2008 were also used to compute the estimated distribution of causes of death, i.e. the cause-specific cumulative risk of death starting at ages $A=30,60$ and 80 and followed to age $a=100$ according to diabetes status and sex. The cumulative risk of death from cause 1 (and similarly for other causes) from age $A$ to age $a$, was calculated as:

$$
F_{1}(a)=\int_{A}^{a} \lambda_{1}(u) S(u) \mathrm{d} u
$$

where $\lambda_{1}$ is the mortality rate from cause 1 . The survival function $S(a)$, was calculated as:

$S(a)=\exp \left(-\int_{A}^{a} \lambda_{1}(u)+\lambda_{2}(u)+\ldots+\lambda_{5}(u) \mathrm{d} u\right)$

The statistical model for the rates was used to estimate the cause-specific rates every $1 / 20$ year from age 30 to age 
Table 1 Causes of death in five and 18 categories and the number of deaths from the different causes between 1 January 1995 and 31 December 2008

\begin{tabular}{|c|c|c|c|c|c|c|}
\hline \multirow[t]{3}{*}{ ICD-10 codes } & \multicolumn{2}{|l|}{ Cause of death } & \multicolumn{4}{|c|}{ Number of deaths } \\
\hline & \multirow[t]{2}{*}{ Five categories } & \multirow[t]{2}{*}{18 categories } & \multicolumn{2}{|l|}{ Males } & \multicolumn{2}{|l|}{ Females } \\
\hline & & & Non-DM & DM & Non-DM & $\mathrm{DM}$ \\
\hline & Cancer & & 93,037 & 14,503 & 93,096 & 11,580 \\
\hline $\mathrm{C} 34$ & & Lung cancer & 24,327 & 3,276 & 18,953 & 1,946 \\
\hline $\mathrm{C} 18-\mathrm{C} 20$ & & Colorectal cancer & 11,842 & 1,835 & 12,306 & 1,543 \\
\hline $\mathrm{C} 50$ & & Breast cancer & 117 & 22 & 16,542 & 1,853 \\
\hline C61 & & Prostate cancer & 13,196 & 1,893 & 0 & 0 \\
\hline $\mathrm{C} 22$ & & Liver cancer & 1,672 & 619 & 1,220 & 245 \\
\hline $\mathrm{C} 25$ & & Pancreatic cancer & 3,830 & 1,322 & 4,444 & 1,180 \\
\hline \multirow{2}{*}{$\begin{array}{l}\mathrm{C} 00-\mathrm{C} 17, \mathrm{C} 19, \mathrm{C} 21, \mathrm{C} 23-24, \mathrm{C} 26-\mathrm{C} 33, \\
\mathrm{C} 37-\mathrm{C} 49, \mathrm{C} 51-\mathrm{C} 60, \mathrm{C} 62-\mathrm{C} 97, \mathrm{D} 00-\mathrm{D} 09\end{array}$} & & Other cancers & 38,053 & 5,536 & 39,631 & 4,813 \\
\hline & Cardiovascular diseases & & 96,199 & 20,380 & 103,497 & 19,598 \\
\hline I20-I25 & & Ischaemic heart disease & 49,659 & 11,500 & 45,451 & 9,924 \\
\hline I60-I69 & & Cerebrovascular diseases & 24,127 & 4,804 & 33,514 & 5,675 \\
\hline I00-I15, I26-I52, I70-I99 & & Other cardiovascular diseases & 22,413 & 4,076 & 24,532 & 3,999 \\
\hline E10-E14 & Diabetes & Diabetes & 228 & 9,774 & 242 & 7,809 \\
\hline \multirow[t]{2}{*}{ N17-N19 } & Renal failure & Renal failure & 1,825 & 485 & 1,469 & 387 \\
\hline & Other causes & & 119,161 & 20,069 & 139,266 & 19,625 \\
\hline A00-B99 & & Infectious diseases & 3,220 & 708 & 3,414 & 748 \\
\hline J00-J99 & & Respiratory diseases & 30,540 & 4,865 & 34,578 & 4,820 \\
\hline K00-K93 & & Digestive diseases & 15,439 & 3,454 & 16,407 & 2,879 \\
\hline N00-N16, N20-N99 & & Other genitourinary diseases & 2,584 & 569 & 2,813 & 563 \\
\hline V01-Y98 & & External causes & 15,772 & 1,914 & 13,249 & 1,626 \\
\hline $\begin{array}{l}\text { D10-D89, E00-E07, E15-E90, F00-H95, } \\
\text { L00-M99, O00-T98, Z00-U99 }\end{array}$ & & Other causes & 51,606 & 8,559 & 68,805 & 8,989 \\
\hline
\end{tabular}

See ESM Figs 1-8 for analyses by 18 causes of death

DM, diabetes mellitus

100, and these were used to compute the integrals as cumulated sums.

When calculating the cumulative risk of death, it was assumed that individuals without diabetes could not get diabetes later in life; i.e. the diabetes incidence rates were assumed to be zero. When the cross-sectional rates are used to obtain the cumulative risk of death, the cumulative risk of death does not reflect the risk of death in a birth cohort because the cumulative risks are based on experiences from many different cohorts. The cross-sectional rates were used to obtain the cumulative risk of death among persons at different ages $(30,60$ or 80 years) by assuming that the agespecific cross-sectional rates (from 2008) applied throughout life. This parallels the standard way in which expected lifetime is calculated in official publications.

The estimated cumulative risk of death from all causes at age 100 was slightly less than $100 \%$, so the distribution of causes of death (at age 100) was rescaled to sum to $100 \%$.
The empirical distribution of causes of death in the observation period was compared with the estimated distribution in order to illustrate the necessity of using a proper model.

The years of life lost due to diabetes was computed to see how much diabetes shortens life and which causes of death lead to most years of life being lost. Estimated years of life lost due to diabetes from cause $1\left(L L_{1}\right)$ at age $a$ was computed by subtracting the cumulative risk of death from cause 1 between age $a$ and age 100 among persons without diabetes from the cumulative risk of death from cause 1 among diabetic patients between the same ages:

$\begin{aligned} L L_{1}(a)= & \int_{a}^{\infty} \mathrm{P}\{\text { dead from cause } 1 \text { before } u \mid \text { diabetes \& alive at } a\} \\ & -\mathrm{P}\{\text { dead from cause } 1 \text { before } u \mid \text { no diabetes \& alive at } a\} \mathrm{d} u\end{aligned}$

The death probability from cause 1 between age $a$ and $u$ among diabetic patients (and similarly for persons without diabetes) was computed as: 
$\mathrm{P}\{$ dead from cause 1 before $u \mid$ diabetes at $a\}$

$$
=\int_{a}^{u} \lambda_{1, \text { dia }}(x) S_{\text {dia }}(x) / S_{\text {dia }}(a) \mathrm{d} x
$$

Total years of life lost due to diabetes $\left(L L_{a}\right)$ at age $a$ were computed as the sum of years of life lost from each specific cause of death at age $a$ :

$$
L L_{a}(a)=L L_{1}(a)+L L_{2}(a)+L L_{3}(a)+L L_{4}(a)+L L_{5}(a)
$$

This gives the same number as if $L L_{a}$ were based on total mortality.

Tabulation of deaths from the registers was carried out in SAS (Cary, NC, USA), version 9.1. All the statistical analyses and graphs were done in R, version 2.12.0 (www. R-project.org/).

\section{Results}

During the 14-year study period from 1 January 1995 to 31 December 2008, patients with diabetes contributed 2,276,450 person-years of follow-up, and persons without diabetes contributed 45,077,431 person-years. During follow-up, 124,210 individuals with and 648,020 individuals without diabetes died.

In Table 1, the number of deaths from specific causes, categorised into five and 18 categories, are shown. Only results for the five causes of death are shown in this section (whereas the results for the 18 causes of death can be found in the electronic supplementary material [ESM] Figs 1-8).

Age-specific mortality rates In Fig. 1, the age-specific mortality rates are shown for all causes and for the five specific causes of death. The mortality rates for all causes and the specific causes of death increased largely exponentially with age, but for the highest ages the mortality rates stabilised and even showed a tendency to decrease a little for cancer. The highest mortality rates were seen for cardiovascular diseases and other causes of death independent of diabetes status and sex (Fig. 1).

There were also recorded deaths from diabetes among persons without diabetes (see also Table 1). This is presumably due to missing registrations in the Danish National Diabetes Register of persons with diabetes or to misclassification of the cause of death on the death certificate. Therefore death from diabetes among those without diabetes is not further discussed, although it enters the calculation.

Age-specific mortality rate ratios In Fig. 2, the age-specific mortality rate ratios (diabetes vs no diabetes) are shown.

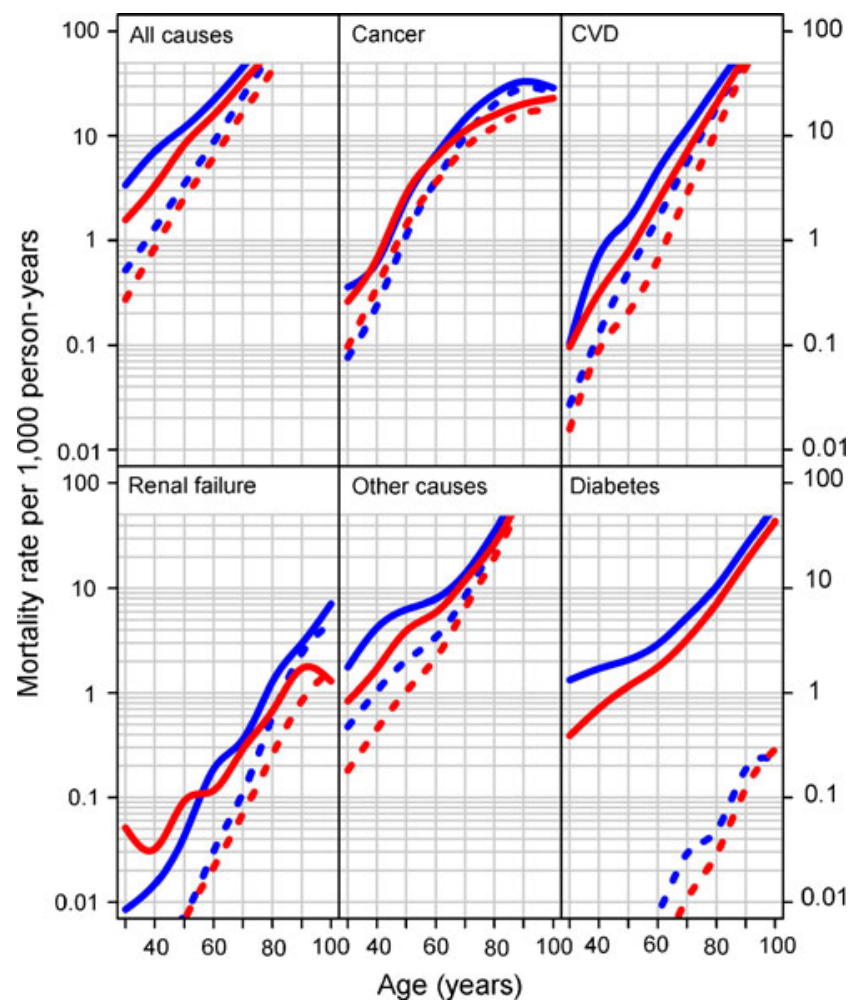

Fig. 1 Age-specific mortality rates. Blue, men; red, women; solid lines, with diabetes; dotted lines, without diabetes. Based on all deaths between 1 January 1995 and 31 December 2008. CVD, cardiovascular diseases. See ESM Figs $1-8$ for the results by subdivision for 18 causes of death

Mortality rates were higher among individuals with diabetes than among those without diabetes for all causes of death and for the specific causes of death. The rate ratios (diabetes vs no diabetes) decreased with age, particularly for renal failure and cardiovascular diseases. The highest rate ratios were seen for renal failure and cardiovascular diseases, the latter having rate ratios of about 3.5 at age 50 and 1.3 at age 90, whereas the rate ratio for cancer deaths was about 2.3 at age 50 and 1.2 at age 90 .

The effect of sex on the association between diabetes and mortality varied with age and cause of death, but from age 50 the mortality rate ratio was higher among females than males from cardiovascular diseases, renal failure and other causes of death, although almost the same for cancer and all causes.

Change in mortality rates over time Mortality rates decreased or remained stable over time except for renal failure, for which the mortality rate seemed to increase over time (Fig. 3). The mortality rates decreased more steeply among patients with diabetes over time than among persons without diabetes for all causes of death as well as for other causes of death, in particular cardiovascular death, whereas the temporal change in cancer mortality was similar. 


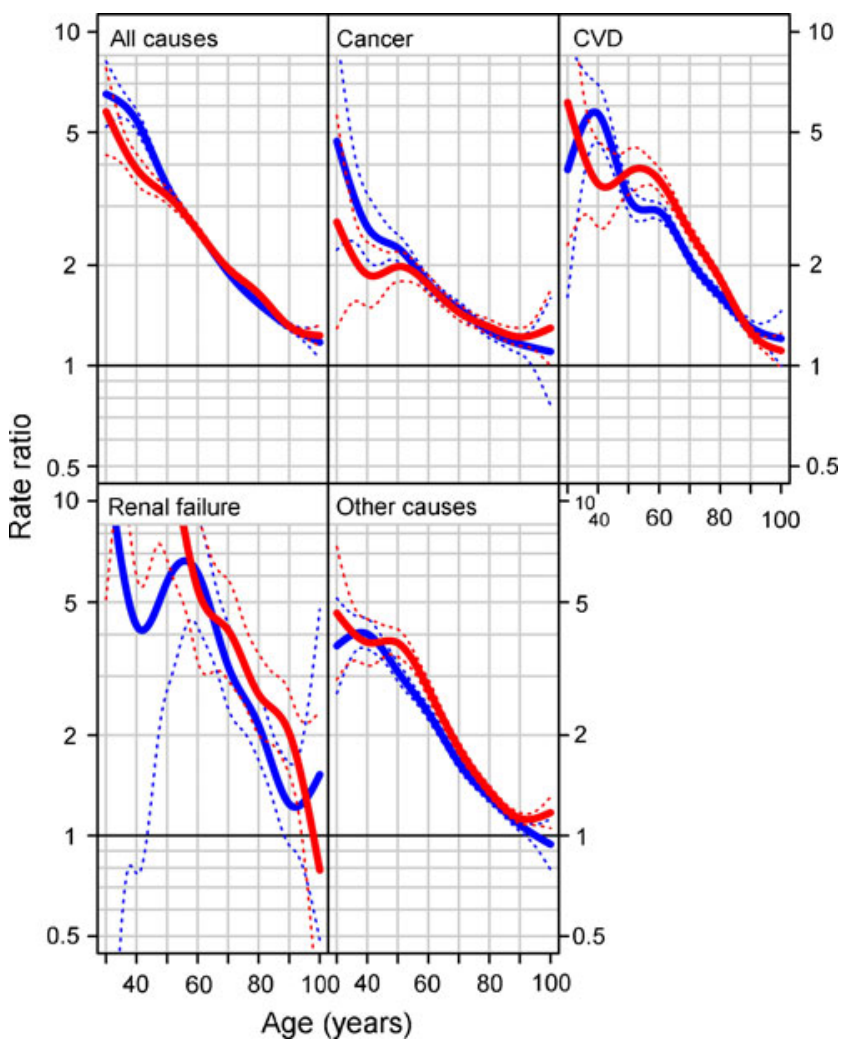

Fig. 2 Age-specific rate ratios (solid lines) and 95\% CI (dotted lines) for patients with diabetes compared with persons without diabetes. Blue, males; red, females. Based on all deaths between 1 January 1995 and 31 December 2008. CVD, cardiovascular diseases. See ESM Figs 1-8 for the results by subdivision for 18 causes of death

Therefore the mortality rate ratio (diabetes vs no diabetes) was higher in previous years for all causes of death, other causes of death and cardiovascular diseases (Fig. 3).

Estimated distribution of causes of death In Fig. 4, the estimated distribution of causes of death is shown. For persons alive at age 30, the lifetime risk of death (death before age 100) from cancer and cardiovascular diseases were both approximately $25 \%$ independent of sex and diabetes status. The lifetime risk of death from other causes was around $40 \%$ among patients with diabetes (males 38\%, females $40 \%$ ) and a little below 50\% among persons without diabetes (males $45 \%$, females $48 \%$ ).

The largest difference between those with and without diabetes was that individuals with diabetes had a lifetime risk of approximately $12 \%$ of dying from diabetes, which was mainly compensated by the lower lifetime risk of death from other causes among this group (Fig. 4). When diabetes was disregarded as a cause of death, the lifetime risk of death from the specific causes was almost the same among those with and without diabetes (results not shown).

Compared with persons alive at age 30 , those alive at age 60 had approximately the same distribution of causes of

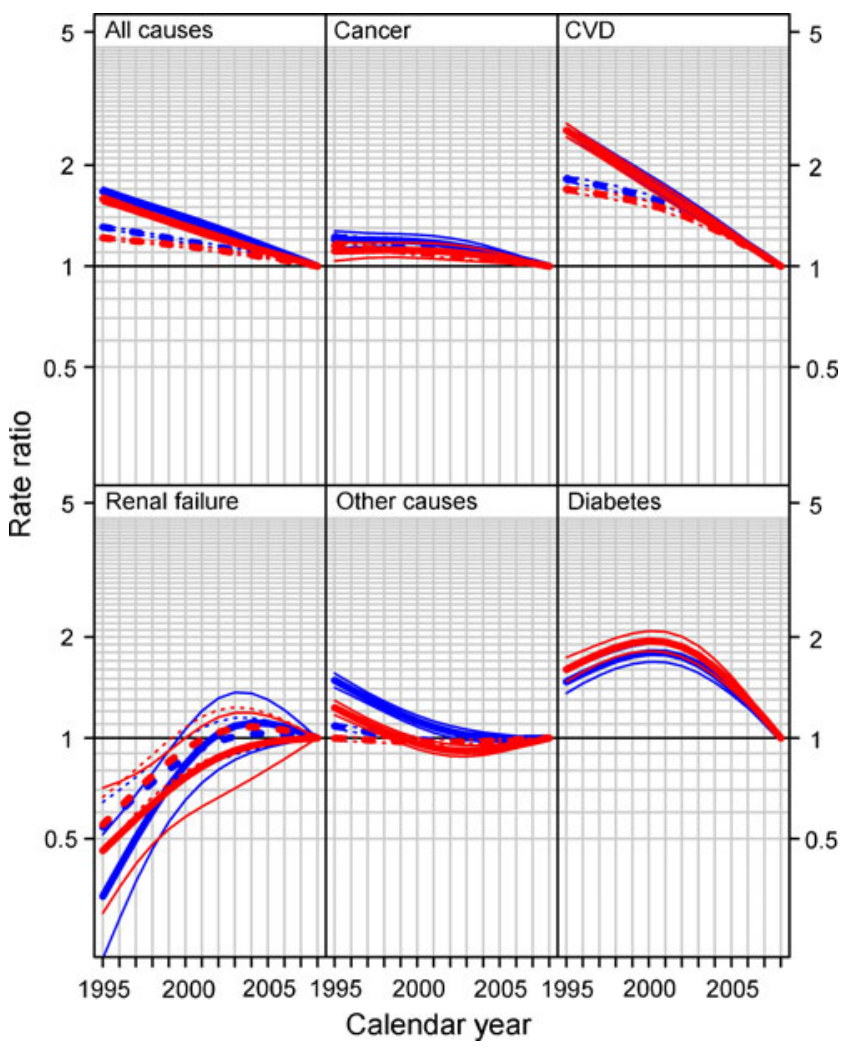

Fig. 3 Rate ratios relative to 2008 (thick lines) by calendar year and 95\% CI (thin lines). Blue, males; red, females; solid lines, with diabetes; dotted lines, without diabetes. Based on all deaths between 1 January 1995 and 31 December 2008. CVD, cardiovascular diseases. See ESM Figs 1-8 for the results by subdivision for 18 causes of death

death, whereas those alive at age 80 had a lower lifetime risk of death from cancer and diabetes (among diabetic patients), and a higher lifetime risk of death from cardiovascular diseases and other causes (Fig. 4).

Estimated and empirical distribution of causes of death When the empirical distribution of causes of death was compared with the estimated distribution, it was clear that the empirical fraction of deaths from cardiovascular diseases was higher than that estimated, independent of diabetes status and sex (Fig. 5). Among patients with diabetes, the empirical fraction of deaths from cancer was lower than that estimated. These differences largely reflect the age distribution of the population, where the empirical calculations tend to put more weight on the older age classes.

Estimated years of life lost due to diabetes Patients with diabetes lost years of life from almost all the specific causes of death. Male and female diabetic patients aged 30 lost on average 9.6 and 8.1 years of life, respectively (Fig. 6). The total number of years of life lost due to diabetes decreased as age increased and was below 1 year among those aged 

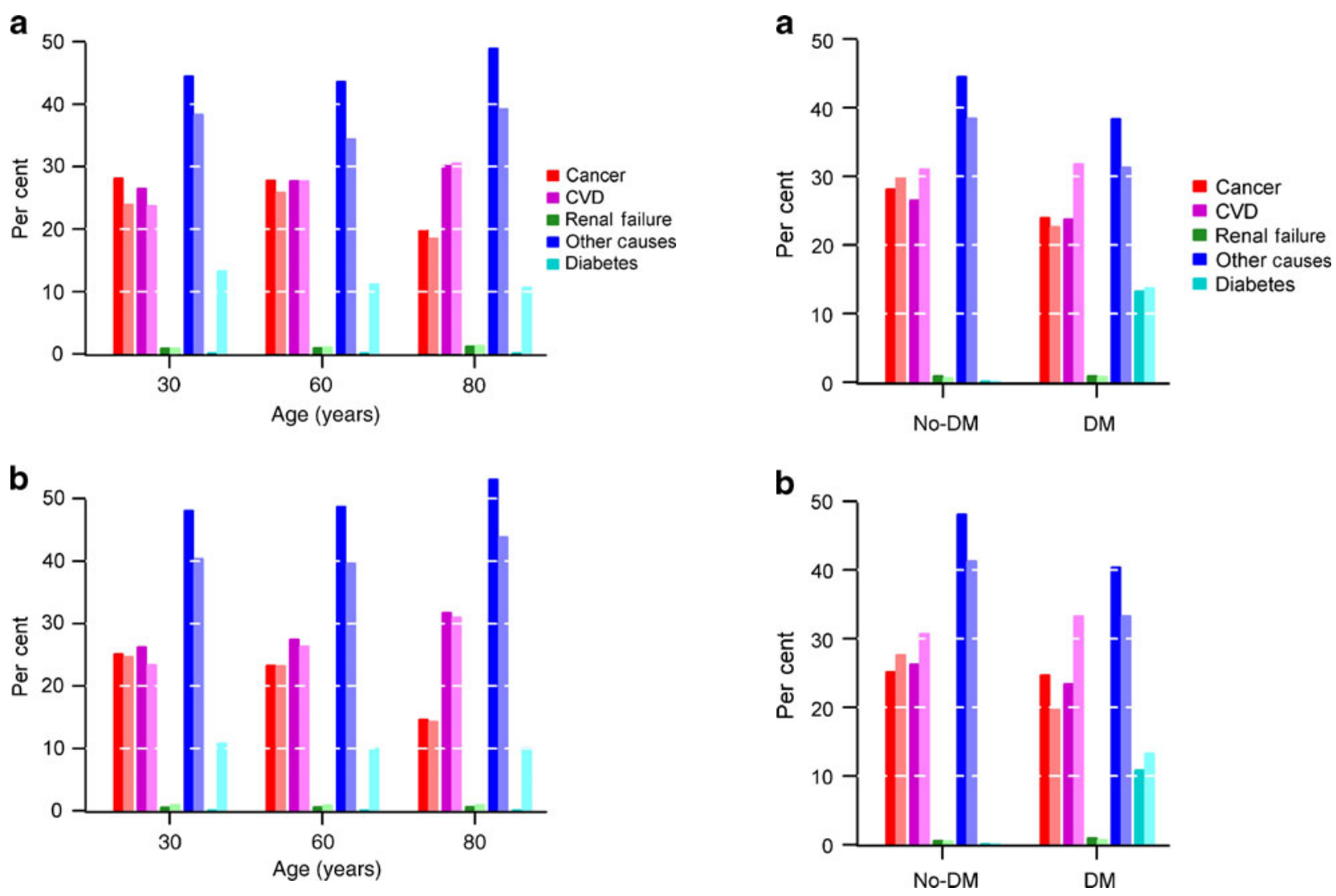

Fig. 4 Estimated distribution of causes of death among those alive at age 30,60 and 80 years. For each pair of bars, the darker coloured bars on the left denote persons without diabetes, and the lighter coloured bars on the right denote those with diabetes. a Men, b women. See ESM Figs 1-8 for the results by subdivision for 18 causes of death

90. The higher mortality among diabetic patients was primarily caused by a higher mortality from diabetes (males 4.7 years lost, females 3.1 years lost).

The oldest individuals with diabetes did not, however, die earlier from other causes of death, but did on the contrary die $0.1-0.2$ years later from other causes of death compared with those without diabetes. This is because individuals with diabetes had a higher risk of death from diabetes that was primarily compensated by a lower risk of death from other causes of death.

\section{Discussion}

In our study, diabetes was associated with higher mortality from all the specific causes of death, but the distribution of causes of death was similar for persons with and without diabetes. A higher mortality among individuals with diabetes than without diabetes is supported by the findings of several previous studies $[1,4,17]$. In our study, the highest mortality rate ratios were for cardiovascular diseases

Fig. 5 Estimated compared with empirical distribution of causes of death for those alive at age 30 years. For each pair of bars, the darker coloured bars on the left denote estimated distributions, and the lighter coloured bars on the right are empirical distributions. a Men, b women. DM, diabetes mellitus. See ESM Figs $1-8$ for the results by subdivision for 18 causes of death

and renal failure, which was also found in previous studies $[4,6,7]$. This is not surprising since the main complications of diabetes include cardiovascular and renal disease [18].

In our study, the cause-specific rate ratios decreased with increasing age, which means that diabetes is most harmful at younger ages. The reason why the rate ratio decreased with increasing age for most causes of death is most likely that persons without diabetes in the younger age groups are in general healthy and have a very low mortality. Therefore even a small harmful effect of diabetes on the body will cause a high relative mortality among those with diabetes compared with those without it at younger ages. Another way of explaining the decreasing mortality rate ratio with increasing age is by the concept of 'frailty', meaning that the healthiest patients with diabetes will be most likely to survive to older ages. At older ages, the average duration of diabetes is also longer among the patients remaining alive, and some previous studies have found that the mortality rates decreased with a longer duration of diabetes [7, 15]. It must, however, be kept in mind that it is not a cohort of diabetic patients who are 


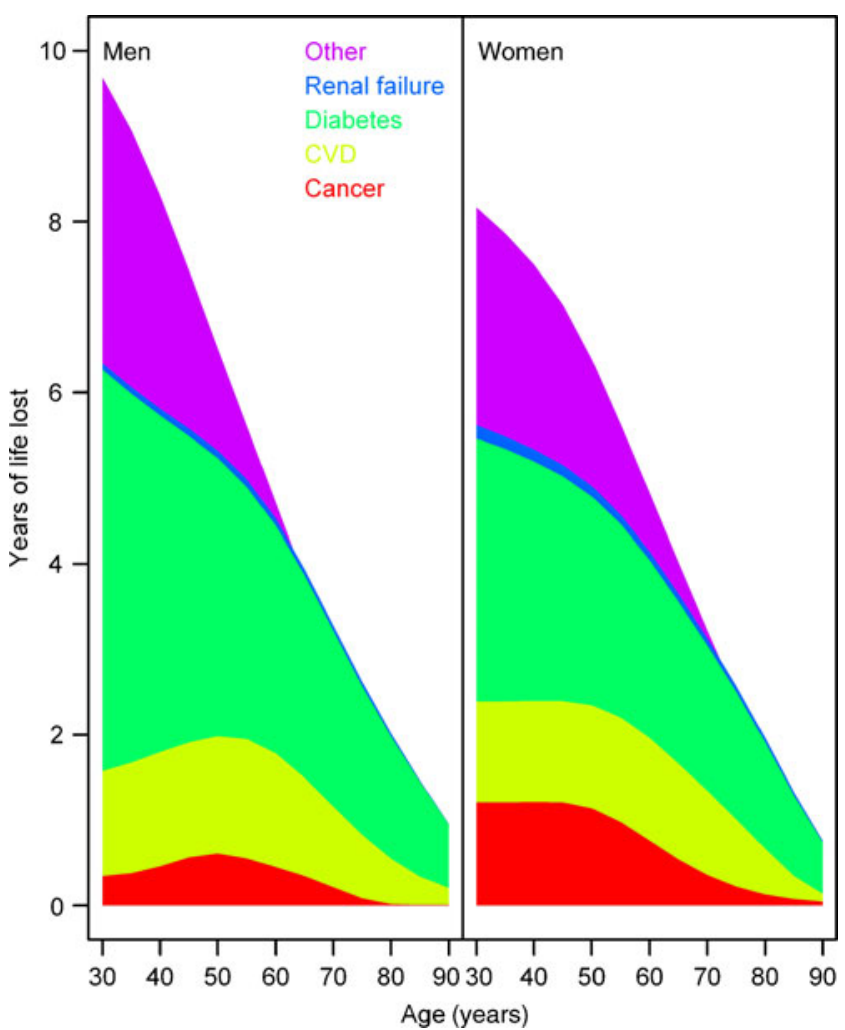

Fig. 6 Years of life lost due to diabetes from different causes of death in different ages. See ESM Figs 1-8 for the results by subdivision for 18 causes of death

followed through life in this study, and therefore some diabetic patients are diagnosed late in life and are not necessarily the healthiest (least frail) group of those with diabetes.

The mortality rates from cardiovascular diseases among diabetic patients decreased more steeply over time (19952008) than it did among persons without diabetes. This is likely to be explained by a combination of earlier diagnosis (and thereby a healthier diabetes population) and better treatment of diabetes and its complications over time. In Denmark, initiatives were set up over the period 1995-2008 to improve the treatment and reduce the complications of diabetes, including initiatives from the Danish government and the National Board of Health in Denmark [19, 20]. These initiatives are likely to influence the mortality from cardiovascular diseases most and to a lesser degree death from cancer and other causes.

In this study, the estimated distribution of causes of death was not the same as the empirical distribution of causes of deaths. The empirical fraction of cardiovascular deaths was higher than the estimated fraction of cardiovascular death (see Fig. 5). The estimated distribution of deaths refers to a hypothetical cohort followed from birth to death. The empirical distribution of deaths in the 14-year period of the study is, in contrast to the estimated values, influenced by the age distribution of the population, which has an over-representation of individuals from the large birth cohorts of the 1940s.

This study has several strengths. First, it covers a recent time period and the entire Danish population from age 30 to 98 , and is therefore among the largest studies looking at the association between diabetes and cause-specific mortality.

Another strength of the study is that all causes of death were studied, and because of the large study population, it was possible to study the association between diabetes and many specific causes of death stratified by age and sex and still obtain relatively precise estimates. Therefore we were able to apply a more detailed cause of death classification than was the case for most previous studies.

A third strength is the absence of known diabetes in the reference group. Thus, the estimated rate ratios in this study are a more valid representation of the true risk of diabetes on mortality than are the standardised mortality ratios (SMRs) reported in most previous studies, where the reference population also includes individuals known to have diabetes. This is of importance with diabetes as the prevalence of diabetes is $15-20 \%$ in ages over 70 [15]. Moreover, we reported the mortality rate ratio by age, showing a substantial age effect, which means that any overall SMR or mortality rate ratio is largely meaningless because it will be a weighted mean of the SMRs or rate ratios for different ages weighted with the population's age distribution, which clearly has no biological meaning.

Fourth, there is no selection bias as the entire population was included. Loss to follow-up is also not a problem since the registers cover the entire population and only a very small proportion of the Danish population - approximately $1 \%$ - emigrate each year [21].

Many previous studies have looked at death certificates to determine diabetes status, but these have been found to underestimate the number of individuals with diabetes because of an under-recording of diabetes on death certificates [22-26]. Other studies have relied on selfreported diabetes status, but this is also not very reliable either since the under-reporting of diabetes status has been found to be in the range $17-44 \%$ in some previous studies [27-29]. A strength of this study is therefore that diabetes status was determined by registration on the Danish National Diabetes Register, an early edition of the register having been found to have a positive predictive value and sensitivity of almost $90 \%$ [30]. It would, however, have been optimal to determine the diabetes status from clinical measurements, but that would have made it impossible to study the entire Danish population.

Cause of death was determined from the Cause of Death Register, which is based on death certificates. The validity of the cause of death registrations can be questioned because previous studies have found that subsequent 
autopsies revealed an incorrect registration of the cause of death on a relatively high proportion of death certificates [31-34]. This is, however, a problem for all studies relying on death certificates to determine the cause of death. Over the period 1996-2005, autopsies were performed for approximately $2.5 \%$ of all deaths in Denmark. In 2005, the total autopsy frequency was $2.6 \%$. Depending on age, the autopsy frequency was $17 \%, 35 \%, 11 \%$ and $1 \%$, respectively, for those aged 0-19 years, 20-39 years, 4059 years and $60+$ years [35]. Incorrect registration of cause of death will obscure the cause-specific mortality rates. This problem is probably largest in those aged 60 years or over due to the low autopsy frequency for this group.

A limitation of the study was, however, the missing information on lifestyle factors, which made it impossible to control for possible confounders. How much of the association between diabetes and cause-specific mortality can be explained by uncontrolled confounding is hard to tell, but a recent study found that diabetes was still associated with an increased mortality even after controlling for many confounding factors such as smoking status and body mass index [6].

A second limitation of the study was that it was not possible to distinguish between types of diabetes. The study included the entire Danish population from age 30 to 98 , and since $80-85 \%$ of Danish patients with diabetes have type 2 diabetes, the study results can be expected largely to reflect the mortality among those with type 2 diabetes [36]. That the results found should be a reflection of the mortality among patients with type 2 diabetes is supported by previous studies. One study including a representative cohort of the US population between 25 and 74 years of age found that when persons who were likely to have type 1 diabetes (diagnosed before age 30) were excluded from the analyses, the mortality rates hardly changed [24]. Another population-based study including participants with type 1 and type 2 diabetes also found that, when excluding patients with type 1 diabetes from the analyses, the SMRs hardly changed [37]. This is to some extent attributable to the fact that those with type 1 diabetes contribute a relatively small fraction of patients.

When considering whether the results are applicable to populations other than the study population, it is important to remember that the study population is a homogenous white population. Several studies have found that the association between diabetes and mortality differs between different ethnic groups, and therefore our results are probably applicable only to similar ethnic populations $[8,9]$. Aside from this, the association between diabetes and mortality is most likely to be dependent on the healthcare system and the diagnosis and treatment options for diabetes, because early diagnosed and well-regulated diabetes is not as harmful as late diagnosed and poorly regulated diabetes [38].
Therefore the results are likely to be applicable only to countries with a healthcare system providing free care for diabetes, such as the Danish system.

In this study, the follow-up period was 14 years. It would be relevant in the future, when longer follow-up data are available, to repeat the study to see what the mortality rates and the cumulative risks of death from different causes are in the different birth cohorts and how this differs according to diabetes status, sex and age.

In conclusion, diabetes was associated with a higher mortality from all the specific causes of death. The mortality rate ratios (diabetes vs no diabetes) for the specific causes of death decreased with age and were higher in previous calendar years compared with 2008 for all causes of death, as well as for cardiovascular diseases and other causes of death. The effect of sex on the association between diabetes and mortality varied with the age and cause of death. Patients with diabetes aged 30 lost approximately 9 years of life compared with persons without diabetes, the corresponding figure for 70-yearolds being 3 years. The distribution of causes of death was similar for those with and without diabetes. The estimated distribution of causes of death was different from the empirical distribution of causes of death, highlighting the necessity of demographic methods to address demographic questions.

Contribution statement $\mathrm{MBH}$ and $\mathrm{BC}$ conceived the idea for the study. MLJ abstracted and tabulated data. MBH was in charge of the statistical analysis and graphics under the supervision of $\mathrm{BC} . \mathrm{MBH}$ was the main force in drafting and revising the paper, while $\mathrm{BC}$ and MLJ contributed critical revision and input; all three authors have approved the final version of the manuscript.

Duality of interest M.B. Hansen has no duality of interest associated with this manuscript. B. Carstensen and M.L. Jensen are stockholders of NovoNordisk and employees at the Steno Diabetes Center, a research hospital owned by NovoNordisk.

\section{References}

1. Dawson SI, Willis J, Florkowski CM, Scott RS (2008) Causespecific mortality in insulin-treated diabetic patients: a 20-year follow-up. Diabetes Res Clin Pract 80:16-23

2. Guzder RN, Gatling W, Mullee MA, Byrne CD (2007) Early mortality from the time of diagnosis of type 2 diabetes: a 5 -year prospective cohort study with a local age- and sex-matched comparison cohort. Diabet Med 24:1164-1167

3. Jansson SP, Andersson DK, Svardsudd K (2010) Mortality trends in subjects with and without diabetes during 33 years of followup. Diabetes Care 33:551-556

4. Koskinen SV, Reunanen AR, Martelin TP, Valkonen T (1998) Mortality in a large population-based cohort of patients with drugtreated diabetes mellitus. Am J Public Health 88:765-770

5. Swerdlow AJ, Jones ME (1996) Mortality during 25 years of follow-up of a cohort with diabetes. Int J Epidemiol 25:1250 1261 
6. The Emerging Risk Factors Collaboration (2011) Diabetes mellitus, fasting glucose, and risk of cause-specific death. N Engl J Med 364:829-841

7. Weiderpass E, Gridley G, Nyren O, Pennello G, Landstrom AS, Ekbom A (2001) Cause-specific mortality in a cohort of patients with diabetes mellitus: a population-based study in Sweden. J Clin Epidemiol 54:802-809

8. Morrish NJ, Wang SL, Stevens LK, Fuller JH, Keen H (2001) Mortality and causes of death in the WHO Multinational Study of Vascular Disease in Diabetes. Diabetologia 44(Suppl 2):S14-S21

9. Patterson CC, Dahlquist G, Harjutsalo V et al (2007) Early mortality in EURODIAB population-based cohorts of type 1 diabetes diagnosed in childhood since 1989. Diabetologia 50:2439-2442

10. Green A, Hougaard P (1984) Epidemiological studies of diabetes mellitus in Denmark. 5. Mortality and causes of death among insulin-treated diabetic patients. Diabetologia 26:190-194

11. Allemann S, Saner C, Zwahlen M, Christ ER, Diem P, Stettler C (2009) Long-term cardiovascular and non-cardiovascular mortality in women and men with type 1 and type 2 diabetes mellitus: a 30-year follow-up in Switzerland. Swiss Med Wkly 139:576-583

12. Soedamah-Muthu SS, Fuller JH, Mulnier HE, Raleigh VS, Lawrenson RA, Colhoun HM (2006) All-cause mortality rates in patients with type 1 diabetes mellitus compared with a non-diabetic population from the UK general practice research database, 1992 1999. Diabetologia 49:660-666

13. CPR-Kontoret (2010) Om CPR-området. Available from www. cpr.dk/cpr/site.aspx?p=16, accessed 25 November 2010.

14. Sundhedsstyrelsen (2010) Registerdekleration for Dødsårsagsregistret. Available from www.sst.dk/Indberetning\%20og\%20statistik/ Doedsaarsagsregisteret.aspx, accessed 20 October 2010.

15. Carstensen B, Kristensen JK, Ottosen P, Borch-Johnsen K (2008) The Danish National Diabetes Register: trends in incidence, prevalence and mortality. Diabetologia 51:2187-2196

16. Sundhedsstyrelsen (2010) Registerdeklaration for Det Nationale Diabetesregister. Available from www.sst.dk/ /media/ Indberetning $\% 200 \mathrm{o} \% 20$ statistik/Sundhedsstyrelsens $\% 20$ registre/ Registerdeklarationer/registerdeklaration $\% 20$ det $\% 20$ nationale $\%$ 20diabetesregister.ashx, accessed 20 October 2010.

17. Skrivarhaug T, Bangstad HJ, Stene LC, Sandvik L, Hanssen KF, Joner G (2006) Long-term mortality in a nationwide cohort of childhood-onset type 1 diabetic patients in Norway. Diabetologia 49:298-305

18. The International Diabetes Federation (2006) The Diabetes Atlas, 3rd edn. Available from www.diabetesatlas.org/sites/default/files/ IDF\%20Diabetes\%20Atlas-2007\%20(3rd\%20edition).pdf, accessed 6 November 2010.

19. Indenrigs- og Sundhedsministeriet (2002) Sund hele livet - de nationale mål og strategier for folkesundheden 2002-10. Indenrigs- og Sundhedsministeriet.

20. Indenrigs- og Sundhedsministeriet (2003) Handlingsplan om diabetes. Indenrigs- og Sundhedsministeriet, Copenhagen

21. Statistikbanken (2011) Nøgletal om befolkningen. Available from www.statistikbanken.dk/statbank5a/default.asp?w=1024, accessed 3 March 2011.
22. Cheng WS, Wingard DL, Kritz-Silverstein D, Barrett-Connor E (2008) Sensitivity and specificity of death certificates for diabetes: as good as it gets? Diabetes Care 31:279-284

23. Andersson DK, Svardsudd K (1994) The value of death certification statistics in measuring mortality in persons with diabetes. Scand J Prim Health Care 12:114-120

24. Gu K, Cowie CC, Harris MI (1998) Mortality in adults with and without diabetes in a national cohort of the U.S. population, 1971-1993. Diabetes Care 21:1138-1145

25. Morgan CL, Currie CJ, Peters JR (2000) Relationship between diabetes and mortality: a population study using record linkage. Diabetes Care 23:1103-1107

26. Sprafka JM, Pankow J, McGovern PG, French LR (1993) Mortality among type 2 diabetic individuals and associated risk factors: the Three City Study. Diabet Med 10:627-632

27. Martin LM, Leff M, Calonge N, Garrett C, Nelson DE (2000) Validation of self-reported chronic conditions and health services in a managed care population. Am J Prev Med 18:215-218

28. Okura Y, Urban LH, Mahoney DW, Jacobsen SJ, Rodeheffer RJ (2004) Agreement between self-report questionnaires and medical record data was substantial for diabetes, hypertension, myocardial infarction and stroke but not for heart failure. J Clin Epidemiol 57:1096-1103

29. Shah BR, Manuel DG (2008) Self-reported diabetes is associated with self-management behaviour: a cohort study. BMC Health Serv Res 8:142

30. Kristensen JK, Drivsholm TB, Carstensen B, Steding-Jensen M, Green A (2007) Validation of methods to identify known diabetes on the basis of health registers. Ugeskr Laeger 169:1687-1692

31. Maclaine GD, Macarthur EB, Heathcote CR (1992) A comparison of death certificates and autopsies in the Australian Capital Territory. Med J Aust 156:462-468

32. Ravakhah K (2006) Death certificates are not reliable: revivification of the autopsy. South Med J 99:728-733

33. Roulson J, Benbow EW, Hasleton PS (2005) Discrepancies between clinical and autopsy diagnosis and the value of post mortem histology: a meta-analysis and review. Histopathology 47:551-559

34. Sington JD, Cottrell BJ (2002) Analysis of the sensitivity of death certificates in 440 hospital deaths: a comparison with necropsy findings. J Clin Pathol 55:499-502

35. Larsen ST, Lynnerup N (2011) Medico-legal autopsies in Denmark. Dan Med Bull 58:A4247

36. Borch-Johnsen K (2007) Diabetes. In: Kjøller M, Juel K, KamperJørgensen F (eds) Folkesundhedsrapporten Danmark 2007. Copenhagen, Statens Institut for Folkesundhed, pp 151-158

37. Raymond NT, Langley JD, Goyder E, Botha JL, Burden AC, Hearnshaw JR (1995) Insulin treated diabetes mellitus: causes of death determined from record linkage of population based registers in Leicestershire, UK. J Epidemiol Community Health 49:570-574

38. Green A, Kyvik KO (2007) Epidemiologi. In: Hilsted J, BorchJohnsen K, Christensen JS (eds) Diabetes. Copenhagen, Munksgaard Danmark, pp 36-46 